\title{
Quantitative evaluation of tongue pressure in children with oral breathing
}

\author{
Elaine Cristina Bezerra dos Santos ${ }^{1}$ \\ https://orcid.org/0000-0001-6385-7683 \\ Hilton Justino da Silva ${ }^{2}$ \\ https://orcid.org/0000-0002-6852-3233
}

Amanda Roselle Cândido Correia ${ }^{1}$ https://orcid.org/0000-0001-7193-8248

Priscila Rossany de Lira Guimarães Portella ${ }^{1}$ https://orcid.org/0000-0001-6674-5097

Daniele Andrade da Cunha ${ }^{2}$ https://orcid.org/0000-0002-3987-9740

Universidade Federal de Pernambuco UFPE, Recife, Pernambuco, Brasil.

2 Universidade Federal de Pernambuco UFPE, Curso de Fonoaudiologia, Recife Pernambuco, Brasil.

Conflict of interests: Nonexistent

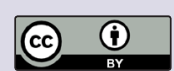

Received on: May 2, 2018

Accepted on: March 6, 2019

Corresponding address:

Elaine Cristina Bezerra dos Santos Avenida Armindo Moura, 581, Quadra B, Bloco 11'a AP. 101 - Boa Viagem CEP: $51130-180$ - Recife, Pernambuco, Brasil

E-mail: elainecfono@gmail.com

\section{ABSTRACT}

Objective: to quantify tongue pressure in children with oral breathing and to describe their respiratory clinical manifestations, comparing them to the objective evaluation

Methods: the study was performed with 60 children, four to nine years old, treated at the outpatient clinics of the Pernambuco Clinical Hospital, Federal University of Pernambuco, distributed into two groups, with and without oral breathing. The collection consisted of a survey of respiratory clinical manifestations, application of the protocol on respiratory mode and assessment of tongue pressure, using the lowa Oral Performance Instrument (IOPI).

Results: male predominance and correlation between diagnosis of allergic rhinitis and/ or nasal obstruction and the clinical diagnosis of oral breathing were observed. There was a statistically significant difference between the groups for usual position of open lips, open mouth, sagging facial expression muscles, narrow nostrils, shortened upper and everted lower lip. The mean tongue pressure in children with oral and nasal breathing presented a mean of $38.27 \mathrm{Kpa}$ and $53.73 \mathrm{Kpa}$, respectively.

Conclusion: tongue pressure decreased in children with oral breathing, corroborating that which is reported in the literature. There was agreement between the results of respiratory clinical characteristics and the objective evaluation.

Descriptors: Oral Breathing; Speech therapy; Child; Tongue 


\section{INTRODUCTION}

Oral Breathing occurs when the subject replaces the nasal respiratory pattern with an oral replacement pattern. It may be related to allergic, genetic factors, inappropriate oral habits and nasal obstruction, being one of the most frequent symptoms in childhood in much of the literature ${ }^{1,2}$.

The child who chronically breathes through the mouth may develop speech disorders, inadequate body posture, changes in the respiratory system, facial deformities and poor positioning of the teeth, resulting in structural changes in the face including lips, tongue, palate and mandible, which will adapt to the new respiratory pattern. With this, the vestibular-tongue balance is removed, altering the balance of the facial muscles and generating an important functional deficiency. Due to the lack of nasal airflow, the pressure of the tongue on the palate is reduced, diverting the mandible downwards and backwards relative to the base of the skull1-5.

The tongue is characterized by an essentially muscular organ, which occupies the functional space of the oral cavity, being formed by a striated muscle tissue, actively participating in processes such as sucking, chewing, swallowing and phonation, fundamental in maintaining quality of life. In view of the importance of this organ, numerous researchers included in their work the measurement of language strength, as a way of quantitatively evaluating their functions ${ }^{6}$.

Oral breathing alters the position of the tongue in the oral cavity, and when the tongue is lowered and anteriorly positioned, it tends to cause changes in the pattern of stomatognathic functions, in addition to failing to exercise its moderating function of the dental arches, favoring more occlusions ${ }^{2}$. According to a study by Rodrigues et al. (2005) ${ }^{7}$, oral respirators presented enlarged and flaccid tongue.

The strength of the tongue can be assessed qualitatively or quantitatively. Qualitative assessment is the most commonly used by professionals in their clinical practice, being subjective and dependent on the professional's common sense and experience and therefore subject to uncertainties related to the human condition of the evaluator. The quantitative evaluation is performed through instruments that provide the value of the strength exerted by the individual, and the IOPI (lowa Oral Performance Instrument) is one of the instruments used for this type of quantitative evaluation ${ }^{8,9}$.

Thus, quantitative assessment increases the probability of appropriate diagnosis of tongue tension in cases of mild force change, being more sensitive to detect small strength differences observed with progression of therapy or disease ${ }^{8}$.

Therefore, the hypothesis of the study is that tongue pressure is lower in children with oral breathing than in children with nasal breathing. Thus, the objective of this study was to quantify tongue pressure in children with oral breathing and to describe their respiratory clinical manifestations, comparing them to objective assessment.

\section{METHODS}

The study was composed of 60 children aged four to nine years, 30 children in each group, oral and nasal breathers. The research was approved by the Committee of ethics and research with human beings of the Federal University of Pernambuco, number 674.637.

It is a comparative, observational, descriptive and cross-sectional study, with a non-probabilistic sampling, for convenience. The research was a reality in children attending Pediatric, Allergology, Endocrinology and Otorhinolaryngology outpatient clinics at the Pernambuco Clinical Hospital (HC), Federal University of Pernambuco (UFPE).

These participants were selected from the inclusion and exclusion criteria. The following were included: Children of both sexes, with and without oral breathing classification, from the application of the respiratory function functional classification protocol elaborated for this research and association with the nosological diagnosis. The following were excluded: Children with neurological impairment, carriers of serious heart diseases, with craniofacial abnormalities present and that were in speech therapy.

Initially, the medical records were reviewed in outpatient clinics to obtain data on nosological diagnosis, treatment and interventions. The control and comparison groups were defined from the medical diagnosis in the medical record. After screening the participants to participate in the study through the exclusion and inclusion criteria, those responsible were informed about the procedure and invited to participate in the study by reading the Free and Informed Consent Term.

Next, the research counted on the application of the protocol developed for research, being composed of data for identification and clinical evaluation of the respiratory mode to assist in the diagnosis of oral breathing. In this protocol, the functional signs and symptoms of respiration and nosological diagnosis are evaluated. 
For the nosologic diagnosis, the presence of allergic rhinitis and mechanical obstruction (adenoidean hypertrophy), both in the chart and the registry of the evaluation of the palatine tonsil sizes by the researcher, were considered, and the mouth was opened with tongue placement out of the tongue out of the oral cavity together with a sound emission /a/.

The sizes of the tonsils were marked on the evaluation card the graduation of the tonsils according to Brodsky's classification. According to this scale, the size of the tonsils was classified as: grade 1 - tonsils inside the tonsillar store, with difficult visualization, being located posterior to the anterior tonsillar pillar; grade 2 - easily visible tonsils behind the posterior tonsillar pillar; grade 3 - tonsils occupying three quarters of the distance to the midline (uvula); grade 4 - completely obstructing tonsils and touching ${ }^{10}$.

The assessment of tongue pressure was performed using the lowa oral performance instrument (MODEL 2.3), which consists of an instrument used to measure and quantify tongue pressure. This instrument is formed from a portable manometer connected to a pressure lamp or tongue-filled air-filled sensor of 2.7 milliliters that is positioned between the tongue and hard palate. The pressures are obtained and displayed digitally by a series of LED lights (expressed in $\mathrm{kPa}$ ) on an LCD panel on the instrument ${ }^{11}$, as shown in Figure 1.

The lingual sensor was positioned against the palatine vault, located in the upper wall of the mouth.
Where the lingual sensor was connected and positioned between the dorsum of the tongue and the hard palate of the individuals evaluated (Figure 2) and asked to perform a maximum tongue pressure against the bulb pressed towards the palate for about two seconds. During the procedure, verbal reinforcement was offered to obtain a higher level of pressure.

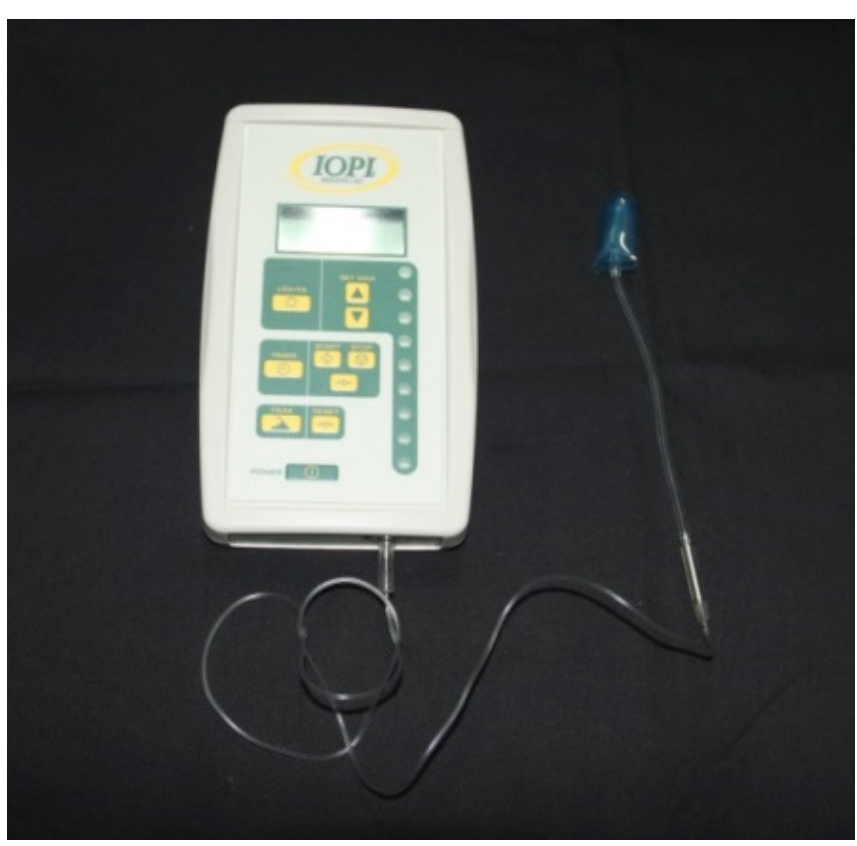

Source: Own (2014).

Figure 1. IOPI (Model 2.3)

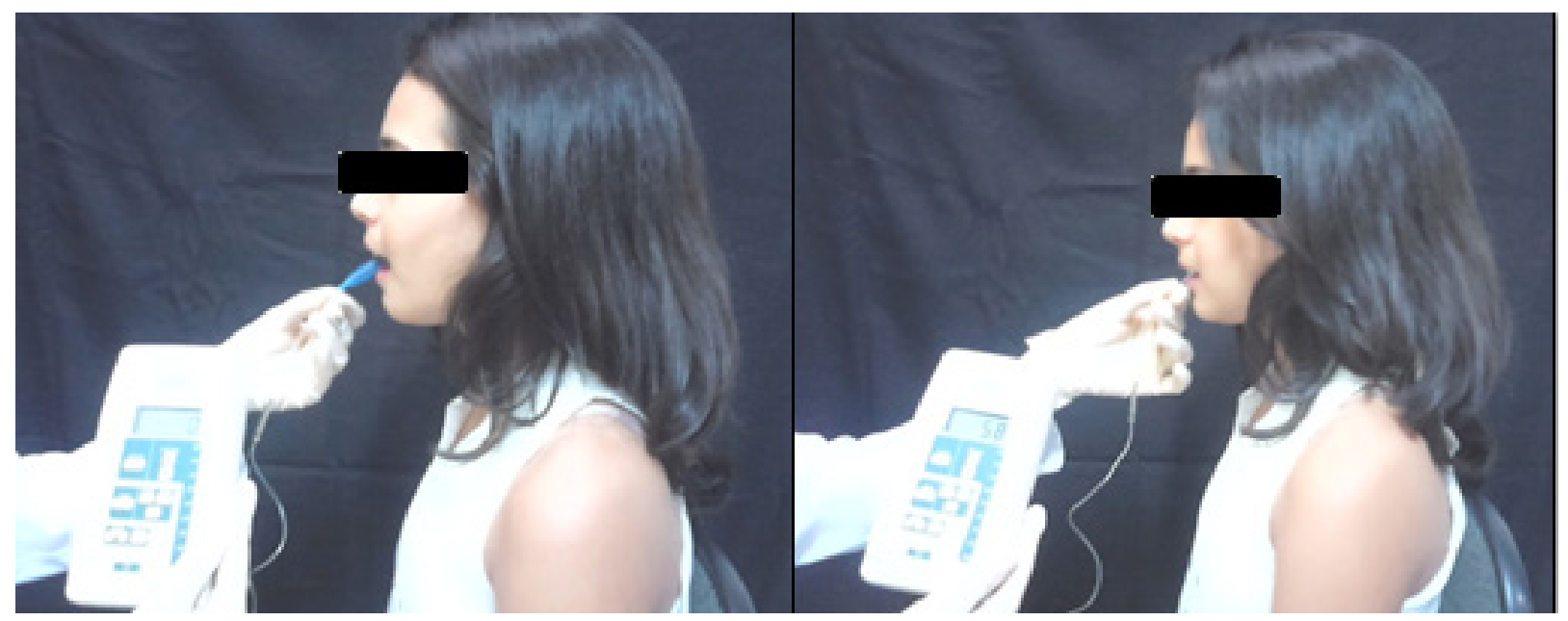

Source: Own (2014).

Figure 2. Steps for placing the bulb in the oral cavity 
Once the participant pressed the sensor the maximum and the effort ceased, the value displayed on the LCD screen of the IOPI device was noted. The patient was advised to rest for 40 seconds, so that the continuation consisted of the repetition of the steps already described three times.

The maximum tongue pressure was the highest recorded pressure on the LCD screen and the mean pressure consisted of the arithmetic mean during the three phases. These results were recorded by the researcher.

The statistical tests for this analysis were chi-square and Fisher's exact test. Statistical analysis was performed using the statistical program SPSS v.17. For all tests the level of significance was $5 \%$.

\section{RESULTS}

Table 1 shows data on the distribution of respiratory clinical manifestations over respiratory mode. It is possible to observe that more than $73.3 \%$ of the children in the oral breathing group had a significant difference in the manifestations of daytime and nighttime oral breathing, frequent colds, snoring, nocturnal sialorrhea and dry throat sensation upon awakening.

There was no statistically significant difference between the groups with oral and nasal breathing in relation to asthma, bronchitis, nocturnal apnea, being fatter than the other children and difficulty chewing.

Regarding sex and respiratory mode, there was a higher prevalence of males in the group of mouth breathers $(n=18)$ and females in the nasal respirators group $(n=15)$.

Table 1. Distribution of respiratory clinical manifestations according to respiratory mode

\begin{tabular}{|c|c|c|c|c|c|}
\hline \multirow{2}{*}{ Variables } & \multicolumn{2}{|c|}{ Oral $(\mathrm{N}=30)$} & \multicolumn{2}{|c|}{ Nasal $(\mathrm{N}=30)$} & \multirow[t]{2}{*}{ Value of $p^{*}$} \\
\hline & $\mathbf{N}$ & $\%$ & $\mathbf{N}$ & $\%$ & \\
\hline Breathing through the mouth & 30 & $100.0 \%$ & 0 & $0.0 \%$ & $<0.001$ \\
\hline Breathing through the mouth during the day & 22 & $73.3 \%$ & 0 & $0.0 \%$ & $<0.001$ \\
\hline Breathing through the mouth at night & 29 & $96.6 \%$ & 0 & $0.0 \%$ & $<0.001$ \\
\hline Frequent colds & 22 & $73.3 \%$ & 5 & $16.6 \%$ & $<0.001$ \\
\hline Asthma & 5 & $16.6 \%$ & 0 & $0.0 \%$ & $0.052^{\star *}$ \\
\hline Bronchitis & 6 & $20.0 \%$ & 0 & $0.0 \%$ & $0.024^{* *}$ \\
\hline Respiratory Allergies & 19 & $63.3 \%$ & 5 & $16.6 \%$ & $<0.001$ \\
\hline Rhinitis & 19 & $63.3 \%$ & 3 & $10.0 \%$ & 0.001 \\
\hline Restless sleep & 15 & $50.0 \%$ & 5 & $16.6 \%$ & 0.006 \\
\hline Apnea & 5 & $16.6 \%$ & 0 & $0.0 \%$ & $0.052^{* *}$ \\
\hline Snores & 20 & $66.6 \%$ & 1 & $3.3 \%$ & $<0.001$ \\
\hline Drools & 22 & $73.3 \%$ & 1 & $3.3 \%$ & $<0.001$ \\
\hline Wakes up with dry mouth & 21 & $70.0 \%$ & 1 & $3.3 \%$ & $<0.001$ \\
\hline Fatter than the other kids & 2 & $6.6 \%$ & 7 & $23.3 \%$ & $0.145^{\star *}$ \\
\hline Slimmer than the other kids & 15 & $50.0 \%$ & 6 & $20.0 \%$ & 0.015 \\
\hline Has difficulty chewing & 6 & $20.0 \%$ & 0 & $0.0 \%$ & $0.024^{* *}$ \\
\hline
\end{tabular}

NASAL $=$ nasal breathing patient group; ORAL $=$ group of oral breathers. Legend: ${ }^{*} p<0.05$ (Chi-square test); \%: percentage.

Table 2 presents data on respiratory signs and symptoms in children with oral and nasal breathing. There was a statistically significant difference with greater relevance in children with oral breathing, in the data on habitual position of the parted lips, open mouth, flaccidity of facial expression muscles, narrow nostrils, shortened upper lip and everted lower. There was no significant difference between the two groups regarding halitosis, whitish tongue, daytime sleepiness, difficulty maintaining alertness and reduced appetite. 
Table 2. Distribution of respiratory clinical manifestations, according to signs and symptoms related to respiratory mode

\begin{tabular}{|c|c|c|c|c|c|}
\hline \multirow{2}{*}{ Variables } & \multicolumn{2}{|c|}{ Oral $(\mathrm{N}=30)$} & \multicolumn{2}{|c|}{ Nasal $(\mathrm{N}=30)$} & \multirow[t]{2}{*}{ Value of $p^{*}$} \\
\hline & $\mathbf{N}$ & $\%$ & $\mathbf{N}$ & $\%$ & \\
\hline Have dark circles & 19 & $63.3 \%$ & 1 & $3.3 \%$ & $<0.001$ \\
\hline Keep their lips parted & 25 & $83.3 \%$ & 0 & $0.0 \%$ & $<0.001$ \\
\hline Keep their mouth open & 25 & $83.3 \%$ & 0 & $0.0 \%$ & $<0.001$ \\
\hline Feature flaccidness of the face muscles & 23 & $76.6 \%$ & 0 & $0.0 \%$ & $<0.001$ \\
\hline Narrow nostrils & 22 & $73.3 \%$ & 2 & $6.6 \%$ & $<0.001$ \\
\hline Shortened upper lip & 21 & $70.0 \%$ & 0 & $0.0 \%$ & $<0.001$ \\
\hline Everted lower lip & 22 & $73.3 \%$ & 0 & $0.0 \%$ & $<0.001$ \\
\hline Halitosis & 19 & $63.3 \%$ & 11 & $36.6 \%$ & $0.070 * *$ \\
\hline Whitish tongue & 7 & $23.3 \%$ & 0 & $0.0 \%$ & $0.011 * *$ \\
\hline Drowsiness during the day & 16 & $53.3 \%$ & 15 & $50.0 \%$ & $1.000 * *$ \\
\hline Difficulty maintaining attention & 16 & $53.3 \%$ & 9 & $30.0 \%$ & $0.115^{\star *}$ \\
\hline Reduced appetite & 13 & $43.3 \%$ & 9 & $30.0 \%$ & $0.422^{\star \star}$ \\
\hline
\end{tabular}

$\mathrm{NASAL}=$ grupo de pacientes respiradores nasais; ORAL = grupo de pacientes respiradores orais. Legenda: ${ }^{\star} p<0,05$ (teste do Qui-quadrado); \%: percentual.

Table 3 shows the data referring to the nosological diagnosis and the respiratory pattern. A statistically significant relationship was found with mild allergic rhinitis and oral breathing, as well as for moderate nasal obstruction and grade III palatine tonsil.

Table 3. Relationship between nosological diagnosis and respiratory pattern

\begin{tabular}{ccccc}
\hline Variables & Categories & Oral $\mathbf{n}(\%)$ & Nasal $\mathbf{n}(\%)$ & Value of $\mathbf{p}^{*}$ \\
\hline \multirow{2}{*}{ Rhinitis } & Light & $19(63.3 \%)$ & $5(16.6 \%)$ & 0.001 \\
& Moderate & $7(23.3 \%)$ & $2(6.6 \%)$ & 0.005 \\
& Severe & $2(6.6 \%)$ & $0(0.0 \%)$ & 0.005 \\
Diagnosis of nasal obstruction & Light & $10(33.3 \%)$ & $0(0.0 \%)$ & 0.001 \\
(adenoid hypertrophy) & Moderate & $12(40.0 \%)$ & $0(0.0 \%)$ & $<0.001$ \\
& Severe & $1(3.3 \%)$ & $0(0.0 \%)$ & 1.000 \\
& Degree I & $2(6.6 \%)$ & $9(30.0 \%)$ & $0.042^{\star *}$ \\
Palatine Tonsil's classification & Degree II & $14(46.6 \%)$ & $14(46.6 \%)$ & $1.000^{\star *}$ \\
& Degree III & $11(36.6 \%)$ & $4(13.3 \%)$ & 0.037 \\
& Degree IV & $0(0.0 \%)$ & $0(0.0 \%)$ & - \\
\hline
\end{tabular}

NASAL $=$ nasal breathing patient group; ORAL $=$ group of oral breathers. Legend: ${ }^{*} p<0.05$ (Chi-square test); \%: percentage.

The tongue pressure in the group of oral breathers was lower than the nasal respirators group, being $38.27 \mathrm{kPa}$ and $53.73 \mathrm{kPa}$, respectively. There was a significant difference in pressures between the groups, with nasal respirators being responsible for higher levels of tongue pressure.

With regard to gender, tongue pressure was lower in males $(45.70 \mathrm{kPa} \pm 12.01)$ compared to females $(46.37 \mathrm{kPa} \pm 8.11)$, thus raising the possibility that the relation of tongue pressure was lower in males and its prevalence in the group of oral breathers.

\section{DISCUSSION}

Oral breathing is a pathology related to numerous clinical signs and symptoms. There are several causes related to oral breathing, thus, it is understood that there is a relation with several very different diseases, causing its diagnosis and classification not to be very defined ${ }^{12}$. The investigation of oral breathing is fundamental, as it is a condition with potential for the development of complications. In this research, a detailed and specific questionnaire was applied for the characterization of the 
respiratory mode and nosological diagnosis present in the oral respirator.

In the study, two sample groups were considered, that is, the group of oral breathers and the nasal respirators one. The groups were classified according to medical diagnosis and the clinical characteristics found in each sample group were described.

Motonaga, Berte and Lima ${ }^{13}$ (2000) and Imbaud et al. (2006) ${ }^{14}$ agreed with the information found in the research on the characteristics of the child with oral breathing. The authors emphasized that the majority of the children presented complaints of predominantly oral breathing during the day and night, snoring and nocturnal sialorrhea. These symptoms may lead to irreversible changes in the craniofacial growth pattern when established for a long period, mainly in the developmental stage of children, and impair the quality of the child's sleep, presenting xerostomia and restless sleep ${ }^{15,16}$.

According to Cintra, Castro and Cintra (2000) ${ }^{4}$ the occurrence of frequent colds is common in this population, with characteristics of persistent hyaline nasal secretion and sneezing. This information corroborates the findings of the study, where $73.3 \%$ of oral breathers presented this clinical manifestation within the respiratory alterations. Another important finding of the study was the prevalence of children considered to be leaner for their age within the oral breathers group. Some scholars explain that by the altered lip position, the tongue stops pressing the palate and rests on the floor of the mouth and, therefore, the palate becomes ogival and the dental occlusion is compromised $^{4}$. Malposition of the tongue causes chewing and phonation problems. Thus, the child has to chew and breathe at the same time, and eating becomes difficult, eating less and needing liquid to swallow ${ }^{16,17}$.

There were alterations such as dark circles (63.3\%), narrow nostrils (73.3\%), open lips (83.3\%) and morphological changes in the upper and lower lips $(70.0 \%$ and $73.3 \%$, respectively) in children with oral breathing, these data were also cited by other authors as being facial features commonly found in subjects with oral breathing ${ }^{12,13,18,19}$.

Correlating the etiology with the clinical findings, we verified the main causes of oral breathing to allergic rhinitis, Hypertrophy of palatine and pharyngeal tonsils, habit and also associated obstructive pathologies ${ }^{11-13,20,21}$. This study agrees with the findings of these studies, which indicate the incidence of allergic rhinitis (93.3\%) and tonsillar hypertrophy (76.6\%) as concomitant factors of infection and obstruction of the upper airways, favoring nasal obstruction and reduction of nasal airflow.

Among allergic rhinitis, allergic rhinitis deserves to be highlighted, since it affects about 10 to $30 \%$ of the general population, reaching approximately $25.7 \%$ among schoolchildren, from six to 13 years old and because it is evidenced as the main etiological factor of respiration oral ${ }^{4,22-24}$.

A study of 142 oral ventilators of both genders, aged two to 16 years, in the Otorhinolaryngology Outpatient Clinic of the Clinical Hospital of the University of São Paulo, found that $66(46.5 \%)$ of the patients had palatine tonsils degrees III and IV, Brodsky's rank ${ }^{11}$. $\mathrm{n}$ agreement with the study, there was a significant presence of palatine tonsil in grade III in the control group (36.6\%).

Among the instruments for measuring tongue pressure, the lowa Oral Performance Instrument (IOPI) is the most used in scientific research ${ }^{25-29}$, being this instrument used in this research. Comparison of the pressure values found in this research with others in the literature is difficult, since the vast majority use this objective method to evaluate speech functions ${ }^{27}$ and swallowing ${ }^{25,29-33}$, Isometric ${ }^{8,26,30,34}$ and isometric with visual feedback ${ }^{26}$.

In the case of the study conducted by Lambrechts et al. (2010) ${ }^{35}$ the sample included subjects between seven and 44 years of age, where the maximum pressure was measured with a Myometer 160. This type of myometer was manufactured specifically for the measurement of pressure or tension of the intra and perioral muscles in the field of orthodontics. It was observed in this study that the mean tongue pressure was $1.66 \mathrm{~N}$, since it included children from seven years and more than $80 \%$ of the sample was composed of individuals under 18 years of age. This study showed that the strength of the child's tongue is lower than that of the adult, for being, childhood, the stage of body development and maturation of the nervous system.

The study conducted by Perilo $(2007)^{36}$ evaluated the axial force of the tongue in children through subjective and objective means by using an equipment developed at the Federal University of Minas Gerais, comparing them. Fifteen children, of both genders, aged between eight and 12 years old, were distributed between oral pre-surgical respirators, speech therapy and nasal respirators. The lingual force was evaluated by urging children to push their tongue against a spatula and then against the evaluator's gloved finger. 
In this study, Perilo $(2007)^{36}$ classified the lingual force as: adequate, slightly hypotensive, hypotensive or hypertensive. The data from the study revealed the subjective strength of the tongue as hypotensive and slightly hypotensive in the group of pre-surgical oral breathers, followed by oral breathers in SpeechLanguage Pathology. All nasal breathers had adequate tongue strengths. These findings were in agreement with the objective language strength assessment of the research.

In the study by Hermann et al. (2013) ${ }^{37}, 104$ children aged six to ten years and diagnosis of OR were evaluated by a multiprofessional team. Specifically, Speech Therapy subjectively evaluated the tonicity and mobility of tongue, lips and cheeks. In this study, 79 children $(75.9 \%)$ had altered tongue tonus.

In the analysis of the present study, the mean values of tongue pressures in 30 oral and 30 nasal breathers were 38.27 and $53.73 \mathrm{kPa}$, respectively. Thus, we observed a comparison of pressures between the groups, it was considered that the pressures presented by the group of oral breathers present a significant difference of reduced lingual tension, unlike the group with nasal breathing.

Thus, the results found agree with the findings in the literature regarding the diminution of tongue tonus that these subjects present due to the altered respiratory pattern.

Several methods found in the literature refer to instruments used to assess tongue strength ${ }^{7}$. This term is correctly used for instruments that assess tongue pressure over the area. That is, to recognize force it is essential to calculate the area where the pressure detector is positioned or the oral cavity.

In the study, the surface area was not measured and for this reason it is a research to quantify the values of lingual pressure. During the search the expression "force" was found to be more prevalent among instruments with the same objectives. Therefore, there is a lack of studies that assess language pressure in the child population.

According to several authors ${ }^{11,12,19,37-40}$ in relation to sex, it was verified that there is a greater prevalence of males in the groups of oral breathers studied. These findings corroborate with the data found in this study, where $33(55 \%)$ of the evaluated ones were boys.

Thus, the importance of new research to verify language pressures is emphasized, especially in the population of children with oral breathing, since the altered breathing promotes quite different repercussions for these cases.

The data collected in this study point to the importance of the evaluation of signs and symptoms and clinical objective methods in subjects with oral breathing, mainly during childhood, to complement the clinical findings and more reliable therapeutic follow-up.

Analyzing the values of tongue pressure in children with oral breathing and nasal breathing. With the results, it was possible to enrich the literature with quantitative data on language pressure evaluation, contributing to functional evaluation and complementation of the diagnosis data in Orofacial Motricity, allowing the speech-language pathologist to perform a more reliable orofacial myofunctional assessment, to draw specific therapy plans and follow the evolution, observing the pressure gain that the patient obtained, even if this value is imperceptible to the qualitative evaluation. This will make the therapy more stimulating for the patient, increasing their adherence to treatment.

\section{CONCLUSION}

In this study, it was observed that the mean of maximum tongue pressures was lower in the group of individuals with oral breathing. The prevalence was higher in males, and the sample revealed that there is a direct association of the altered respiratory mode with the nosological diagnosis of allergic rhinitis and adenoid nasal obstruction.

There was also agreement between the results of respiratory clinical characteristics and objective evaluation, and the instrument used in this study was shown to be effective in complementing and confirming clinical speech-language findings. However, further studies are necessary, mainly Brazilian ones, involving the IOPI and a greater number of children with and / or without oral breathing, in order to draw the profiles of the expected pressures for each age, gender and respiratory mode.

\section{ACKNOWLEDGEMENTS}

To the research group Pathophysiology of the Stomatognathic System and to all the children who participated in the study.

\section{REFERENCES}

1. Faria PTM, Ruellas ACO, Matsumoto MAN, Anselmo-Lima WT, Pereira FC. Dentofacial morphology of mouth breathing children. Braz Dent. J. 2002;13(2):129-32. 
2. Branco A, Ferrari GF, Weber SAT. Alterações orofaciais em doenças alérgicas de vias aéreas. Rev Paul Pediatr. 2007;25(3):266-70.

3. Abreu RR, Rocha RL, Lamounier JA, Guerra AFM. Etiologia, manifestações clínicas e alterações presentes nas crianças respiradoras orais. Jornal de Pediatria. 2008;84(6):529-35.

4. Cintra CFSC, Castro FFM, Cintra PPVC. The dentalfacial alterations present in mouth breathing. Rev. Bras. Alerg. Imunopatol. 2000;23(2):78-83.

5. Cunha DA, Silva GAP, Motta MEFA, Lima CR, Silva HJ. A respiração oral em crianças e suas repercussões no estado nutricional. Rev. CEFAC. 2007;9(1):47-54.

6. Motta AR, Perim JV, Perilo TVC, Casas EBL, Costa CG, Magalhães FE et al. Método objetivo para a medição de forças axiais da língua. Rev. CEFAC. 2004;6(2):164-9.

7. Rodrigues HOSN, Faria SR, Paula FSG, Motta AR. Occurrence of mouth breathing and orofacial myology disorders in patients on orthodontic treatment. Rev. CEFAC. 2005;7(3):356-62.

8. Furlan RMMM. Desenvolvimento de um aparelho portátil para quantificação e reabilitação da força da língua humana. [Dissertação] Belo Horizonte (MG): Universidade Federal de Minas Gerais, Departamento de Departamento de Engenharia Mecânica, Curso de Engenharia Mecânica; 2011.

9. Lazarus C, Logemann JA, Pauloski BR, Rademaker AW, Helenowski IB, Vonesh EF et al. Effects of radiotherapy with or without chemotherapy on tongue strength and swallowing in patients with oral cancer. Head\&Neck. 2007;29(7):632-7.

10. Granzotto EH. Associação entre o tamanho das tonsilas palatinas e faríngeas com a pressão da artéria pulmonar em crianças. [Dissertação] Porto Alegre (RS): Universidade Federal do Rio Grande do Sul, Programa de pós-graduação em ciências médicas; 2009.

11. Potter NL, Short R. Maximal tongue strength in typically developing children and adolescents. Dysphagia. 2009;24(4):391-7.

12. Di Francesco RC, Passerotii G, Paulucci BM. A. Respiração oral na criança: repercussões diferentes de acordo com o diagnóstico. Rev Bras Otorrinolaringol. 2004;70(5):665-70.

13. Motonaga SM, Berte LC, Lima WTA. A. Respiração bucal: causas e alterações no sistema estomatognático. Rev. Bras. Otorrinolaringol. 2000;66(4):373-9.

14. Imbaud T, Wandalsen G, Nascimento EF, Wandalsen NF, Mallozi MC, Sol D. Respiração bucal em pacientes com rinite alérgica: fatores associados e complicações. Rev. Bras. Alerg. Imunopatol. 2006;29(4):183-7.

15. Câmara JC. Efeitos dos hábitos deletérios sobre o sistema estomatognático. 2010. [Monografia] Montes Claros (MG): Instituto de Ciências da Saúde, Curso de Ortodontia; 2010.

16. Ferraz MJPC, Sousa MAA. Respiração bucal: uma abordagem interdisciplinar. Respire melhor [site na Internet]. 2002 Dec. <http://www.respiremelhor. com.br/odonto/odonto16122002.htm. $>$ Acesso em: out. 2014.

17. Di Francesco RC, Fortes FSG, Komatsu CL. Improvement in the quality of life of children after adenotonsillectomy. Rev. Bras. Otorrinolaringol. 2004;70(6):748-51.

18. Paiva JB. Identificando o respirador bucal. Rev. Assoc. Paul. Cir. Dent. 2000;53(4):265-74.

19. Menezes VA, Leal RB, Pessoa RS, Pontes RMES. Prevalência e fatores associados à respiração oral em escolares participantes do projeto Santo Amaro-Recife, 2005. Rev Bras Otorrinolaringol. 2006;72(3):394-9.

20. Mocellin M. Respirador bucal. In: Petrelli E (ed). Ortodontia para fonoaudiologia, Lovise Científica, 1994. p. 129-44.

21. Bianchini AP, Guedes CF, Hitos S. Respiração oral: causa x audição. Rev. CEFAC. 2009;11(1):38-43.

22. Barros JRC, Becker HMG, Pinto JA. Evaluation of atopy among mouth-breathing pediatric patients referred for treatment to a tertiary care center. Jornal de Pediatria. 2006;82(6):458-64.

23. Ibiapina CC, Sarinho ESC, Camargos PAM, Andrade CR, Cruz Filho AAS. Rinite alérgica: aspectos epidemiológicos, diagnósticos e terapêuticos. J. Bras. Pneumol. 2008;34(4):230-40.

24. Campanha SMA, Freire LMS, Fontes MJF. O impacto da asma, da rinite alérgica e da respiração oral na qualidade de vida de crianças e adolescentes. Rev. CEFAC. 2008;10(4):513-9.

25. Robbins J, Levine R, Wood J, Roecker EB, Luschei E. Age effects on lingual pressure generation as a risk for dysphagia. J Gerontol A Biol Sci Med Sci. 1995;50(5):257-62. 
26. Crow HC, Ship JA. Tongue strength and endurance in different aged individuals. Ship. Journal of Gerontology: Medical Sciences.1996;51(5):247-50.

27. Solomon NP, Robin DA, Luschei ES. Strength, endurance, and stability of the tongue and hand in Parkinson disease. JSLHR. 2000;3(1):256-67.

28. Stierwalt JAG, Youmans SR. Tongue measures in individuals with normal andimpaired swallowing. AJSLP. 2007;16(2):148-56.

29. Clark HM, Henson PA, Barber WD, Stierwalt JA, Sherrill M. Relationships among subjective and objective measures of tongue strength and oral phase swallowing impairments. AJSLP. 2003;12(1):40-50.

30. Robbins J, Gangnon RE, Theis SM, Kays SA, Hewitt $A L$, Hind JA. The effects of lingual exercise on swallowing in older adults. J. Am Geriatr Soc. 2005;53(9):1483-9.

31. Youmans SR, Stierwalt JA. Measures of tongue function related to normal swallowing. Dysphagia. 2006;21(2):102-11.

32. Robbins $\mathrm{J}$. The effects of lingual exercise in stroke patients with dysphagia. Arch phys Med Rehabil. 2007;88(2):150-8.

33. Clark HM, Solomon NP. Age and sex differences in orofacial strength. Dysphagia. 2012;27(1):2-9.

34. Letter M, Santens P, Van BJ. The effects of levodopa on tongue strength and endurance in patients with Parkinson's disease. Acta neurol. belg. 2003;103(1):35-8.

35. Lambrechts $\mathrm{H}$. Lip and tongue pressure in orthodontic patients. Eur $\mathrm{J}$ Orthod. 2010;32(4):466-71.

36. Perilo TVC, Motta AR, Las Casas EB, Saffar JME, Costa CG. Avaliação objetiva das forças axiais produzidas pela língua de crianças respiradoras orais. Rev Soc Bras Fonoaudiol. 2007;12(3):84-90.

37. Hermann JS, Sakai APC, Frutuoso JRC, Fascino SVM, Hitos SF, Cappellette Júnior M. Características clínicas de crianças respiradoras orais. Pediatria moderna. 2013;49(9):385-92.

38. Costa JR, Pereira SRA, Mitri G, Motta JC, Pignatari SSN, Weckx LLM. Relação da oclusão dentária com a postura de cabeça e coluna cervical em crianças respiradoras orais. Rev. Paul Pediatria. 2005;23(2):88-93.

39. Bicalho GP, Motta AR, Vicente LCC. Avaliação da deglutição em crianças respiradoras orais. Rev. CEFAC. 2006;8(1):50-5.
40. Grippaudo C, Paolantonio EG, Antonini G, Saulle R, La Torre G, Deli R. Association between oral habits, mouth breathing and malocclusion. Acta Otorhinolaryngol Ital. 2016;36(5):386-94. 